\title{
Recreation Spatial Equity: An Empirical Study Based on Residents' Experience in Shenzhen
}

\author{
Chunfeng Li, Peng Ju* \\ Shenzhen Tourism College, Jinan University, Shenzhen, China \\ Email:1_cf47407@163.com, *jupeng1976@163.com
}

How to cite this paper: Li, C. F., \& Ju, P. (2020). Recreation Spatial Equity: An Empirical Study Based on Residents' Experience in Shenzhen. Current Urban Studies, $8,320-336$.

https://doi.org/10.4236/cus.2020.82018

Received: May 11, 2020

Accepted: June 7, 2020

Published: June 10, 2020

Copyright $\odot 2020$ by author(s) and Scientific Research Publishing Inc. This work is licensed under the Creative Commons Attribution International License (CC BY 4.0).

http://creativecommons.org/licenses/by/4.0/ (c) (i) Open Access

\begin{abstract}
The paper constructs the recreation spatial equity evaluation system of residents' experience in central urban region and explores the degree of equity in the Futian District of Shenzhen, which is the case study area. The evaluation system adopts the quantitative methods of accessibility theory, which develops a mathematical formula describing the recreation spatial equity from the perspective of quality, time interval and satisfaction. According to the results of accessibility index, the article elaborates on the differences of all kinds of recreation spatial experience of different social classes to survey the reasons of different experience. However, the results from surveys indicate that the differences in the accessibility index of strong class, middle class and weak class are the same. Moreover, the accessibility index of middle class is higher than the other two classes, followed by strong class and weak class. Besides, these results differ from the other previous researches, which refer to the characteristics and allocation of recreation space as well as the preference of residents. In addition, after comparing the accessibility index of different types of recreation space, the paper finds that the equity of public recreation space is better than that of commercial recreation space. As for park, square and commercial recreation space and facilities, the equity of them is much better than those of waterfront recreation space, indoor sports facilities, cultural and educational space, historical and cultural blocks and golf courses.
\end{abstract}

\section{Keywords}

Spatial Equity, Recreation Space, Spatial Experience, Social Class, Central Urban Region 


\section{Literature Review}

\subsection{Urban Recreation}

In the process of modern urban development in the west, the definition of "recreation space" was formed in the $18^{\text {th }}$ century and became an indispensable part of urban construction and planning in the early $20^{\text {th }}$ century. In Athens Charter edited in 1933, four major functions of a city were mentioned as residence, work, recreation and traffic, emphasizing that recreation was one of the indispensable functions. When studying the planning and design of western urban recreation space, $\mathrm{Ma}$ (2005) pointed out that recreation space had close relationship with society, economy, culture and nature. At present, studies on urban recreation space in China still focus on leisure activities from the perspective of tourism. For example, Mao (2014) stated that recreation was an important part of leisure. Qiu (2015) believed that urban leisure space referred to the open space, facilities and buildings for residents to carry out all kinds of leisure and recreation activities. With regard to the classification of recreation space, Chen (2013) divided urban recreation space into five types: recreation belt around metropolis, recreation business district, waterfront recreation space, urban square and green space for recreation. Furthermore, urban public recreation space can be divided with the characters aiming for residents and for tourists and residents. Wei and Xi (2016) divided the urban recreation space into parks, fitness roads, sports venues and others.

\subsection{Definition of Spatial Equity}

A number of western scholars explained the theory of spatial equity from the perspectives of spatial production mechanism and spatial resource allocation. David Harvey was the first scholar who incorporated social justice into the perspective of spatial analysis. Harvey regarded space as the construction of society and regarded historical materialism as the basis of his urban spatial theory. In addition, he analyzed the reasons for the inequity of urban space from the perspectives of economy and politics. From the economic perspective, he argued thatspacewas controlled by the financial capital power owned by a few people, which led to the unfair occupation and distribution of urban spatial resources. From the political perspective, he suggested that urban spatial production led to social stratification and class polarization, which formed the spatial hierarchy (Ren, 2014).

J. B. Kravis, one of American economists, proposed the theory of accessibility and emphasized that the accessibility and deprivation of social resources were two relative aspects when measuring equity. If the accessibility of resources increased, the deprivation of resources relatively would reduce. In the study of quality evaluation of western urban living space, resource accessibility referred to the quantitative weighted sum of the qualities, reachable time and satisfaction of all resources within the maximum distance from the central case study area (Tang, 2014). The western studies on evaluation of resource accessibility have 
gradually deepened, while the Chinese studies on resource accessibility have been at the beginning with no conclusive definition. Wang (2014) stated that spatial equity was based on the needs of the public and the rationality of the layout of facilities so that residents of different classes could enjoy relatively equal services. Cao \& Qiao (2014) and other scholars pointed out that spatial justice regarded space as a material existence and emphasized the importance of the rights for different classes and groups to occupy and use space equally from the perspectives of spatial production and living.

\subsection{Spatial Equity}

The research objects of spatial equity include urban public facilities space and urban green space. With further spatial equity research and the advancement of research tools, including the popularity of GIS software and the development of mathematical statistics method, the research objects gradually move to smaller areas, such as urban communities, blocks, etc. Tan \& Samsudin (2017) studied the relationship between park scales and spatial equity. Kim (2015) measured the recreation opportunity equity of recreation space in the Detroit metropolitan area. Comber, Brunsdon, \& Green (2008) studied the urban green spatial accessibility of different nationalities and religious groups by GIS network analysis. Chinese scholars have also conducted equity studies on public service facilities, parks, urban green space and leisure space at the first step. Wang (2014) conducted an empirical study on the spatial equity of urban public service facilities from the overall level and typical area level by taking public service facilities as the research object. Yin, Kong, \& Zong (2008) introduced spatial accessibility and spatial equity indicators into the functional evaluation of urban green space in an innovative way. Gao, Zhou, \& Ye (2010) conducted a comprehensive equity index model on the spatial distribution of urban public service facilities to explore spatial equity characteristics of urban public service facilities in Guangzhou, China.

Studies on spatial equity mostly base on the geographic information system aiming at the macro level. In western studies, Cutts, Darby, \& Boone et al. (2009) conducted their research with GIS software and found that there were more sports venues and less obese people in the streets and parks with better accessibility. Beeco \& Brown (2013) conducted their research with combined social science data related to space and natural resource allocation with GIS software. Kim (2015) measured the recreation opportunity equity with the quantitative spatial statistical method. Chinese scholars Jiang, Zhou, \& Xiao (2010) studied the characteristics of spatial differences and social equity with the methods of GIS network analysis and buffer analysis. Yin and Xu (2009) firstly quantitatively evaluated the spatial accessibility of parks in the research area with the method of minimum proximity analysis, then analyzed the residents' demand for urban parks with demand index and lastly measured the spatial equity of the park layout in the study area with sequential variable correlation analysis and factor spatial lamination. Mao (2014) proposed the method of spatial equity 
evaluation of community leisure space from the relationship between spatial deprivation and spatial justice in an exploration way. $\mathrm{Wu}$ (2014) constructed a set of evaluation index system of urban tourism community spatial justice and conducted the empirical study with field survey. There also existed studies with interdisciplinary research methods. Tang \& Gu (2015) studied the spatial equity with the combination of economics and geography. They used the Gini coefficient for the overall evaluation of social equity performance and the Lorentz curve method to show the existence of spatial mismatch in public green spatial resources and permanent population.

Studies of spatial equity mostly focus on the perspectives from the relationship between spatial layout and population, spatial accessibility, and studies on spatial equity. However, there exist fewer studies from the perspective of human experience. Erkip (1997) comprehensively evaluated the accessibility and equity of Ankara Park, taking a numbers of parks, population distribution, travel time, and accessibility as indicators with questionnaire surveys, and found that the relationship between park distribution and the needs of different residents groups should be emphasized in order to realize park distribution equity. Bolitzer and Netusil (2000) constructed the model of house prices, distances and types of urban public open space. The results showed that there was a clear correlation with house prices, accessibility and types of urban public open space, quantifying the benefits of maintaining public open space in urban environments. Jiang, Zhong, \& Yu et al. (2015) proposed the method to measure the spatial accessibility of different types of facilities for the elders by combining the distribution density of the elderly population in different streets.

With further studies on spatial equity, various models and theories are constructed to evaluate spatial equity. Western scholars have studied spatial equity from the perspective of accessibility with the Location Theory and constructed various evaluation models such as Gravity Model and Hoover Model based on the GIS platform and resource accessibility model based on resource acquisition ability. Chinese scholars such as Mao (2014) studied the principle of evaluating the community spatial accessibility of community leisure resources. Wu (2014) conducted the empirical study on the spatial justice of the cultural leisure tourism community of the Great Wild Goose Pagoda in Xi'an, China. Chen \& Wang (2009) studied the equity of urban park and proposed the evaluation model of "accessibility - service coverage - service overlap rate - per capita access to park area". Wu, Si, \& Li (2016) proposed the method of evaluating the equity of urban park green space. Hu \& Cai (2017) quantitatively analyzed the equity of urban park service space and mentioned three models of equity evaluation, including the models of buffer zone, cost and interaction.

\section{Research Design}

\subsection{Determination of Evaluation Indicators}

The study area is the central urban region of Shenzhen, China. According to the 
standards of recreation spatial characteristics and commerciality, the area can be divided into public recreation space and commercial recreation space in two first-level indicators, and be further divided into four second-level indicators and ten third-level indicators. The results are shown in Table 1.

\subsection{Quantification of Evaluation Indicators}

Under the guidance of theories of accessibility spatial equity, the qualities, time interval and satisfaction of recreation space visited by residents are quantified in order to understand their accessibility.

Quality accessibility refers to people's evaluation of external environment, atmosphere and facilities of recreation space. Five evaluation criteria, including high, relatively high, medium, relatively low and low, are measured by five scores of " $5,4,3,2,1$ " respectively. The higher the score, the better the quality.

Time interval accessibility refers to the time taken by residents to arrive at the recreation space from their residence. Four evaluation criteria, including 5 - 10 minutes, 10 - 30 minutes, more than 30 minutes, and others, are measured by four scores of " $4,3,2,1$ " respectively. The higher the score, the better the accessibility (Erkip, 1997).

Satisfaction accessibility is mainly measured by whether to meet the recreational needs of residents. Four evaluation criteria, including very satisfied, satisfied, somewhat satisfied, and dissatisfied, are measured by scores of " $4,3,2,1$ " respectively. The higher the score, the better the satisfaction.

Residents who have not been to the recreation space are assigned the score of " 0 ". Meanwhile, the in-depth interviews with them were conducted to further understand the reasons why they have not been there and their impression evaluation of this kind of recreation space.

\subsection{Determination of Weights of Evaluation Indicators}

The importance of different types of recreation space differs in people's daily

Table 1. Classification of recreation space in central urban region of Shenzhen, China.

\begin{tabular}{lll}
\hline First-level indicators & Second-level indicators & Third-level indicators \\
\hline Public recreation space & 1 Public infrastructures & 1.1 Urban parks \\
& & 1.2 Urban squares \\
& 1.3 Urban waterfront recreation space \\
& & 1.4 Sports and fitness venues \\
& 2 Public activities places & 2.1 Indoor cultural and sports facilities \\
& & 2.2 Cultural and educational space \\
& & 2.3 Historical and cultural blocks \\
Commercial recreation & 3 Mass entertainment places & 3.1 Commercial recreation space and commercial facilities \\
& & 3.2 Golf courses \\
& 4 Value-added leisure places & 4.1 Cultural and entertainment places \\
\hline
\end{tabular}


life. Therefore, the weights of different recreation space must be determined to ensure the index equity of recreation spatial accessibility in the overall central urban region of Shenzhen, China. In this study, weights are determined by analytic hierarchy process, including Delphi method of expert questionnaire survey, construction judgment matrix method, consistency test and other methods. The group decision-making of Yaahp 10.0 software is used to calculate the weights of each indicator. The results are shown in Table 2.

The weight of public recreation space is 0.6722 , including two secondary indexes of public infrastructures and public activity places, with the weights of 0.3722 and 0.3000 respectively. Among them, public infrastructures include four indexes of urban parks, urban squares, urban waterfront recreation space and sports and fitness venues. The public activity places include three indexes: indoor cultural and sports facilities, cultural and educational space and historical and cultural blocks.

The weight of commercial recreation space is 0.3278 , including two indexes of mass entertainment places and value-added leisure places, the weight is 0.1920 and 0.1358 respectively. Public entertainment places include golf courses, commercial recreation spaces and commercial facilities. Value added leisure places include cultural and entertainment places.

\subsection{Evaluation System}

According to the quantitative method of accessibility evaluation, the evaluation system of recreation spatial equity in central urban region of Shenzhen based on residents' experience is constructed in this study, which can be seen in Table 1. The index can be calculated by the following two formulas:

Table 2. Weights of indicators

\begin{tabular}{|c|c|c|c|c|c|}
\hline $\begin{array}{l}\text { First-level } \\
\text { indicators }\end{array}$ & Weights & $\begin{array}{l}\text { Second-level } \\
\text { indicators }\end{array}$ & Weights & $\begin{array}{l}\text { Third-level } \\
\text { indicators }\end{array}$ & Weights \\
\hline \multirow{7}{*}{$\begin{array}{c}\text { Public } \\
\text { recreation } \\
\text { space }\end{array}$} & \multirow[t]{7}{*}{0.6722} & \multirow{4}{*}{$\begin{array}{l}\text { Public } \\
\text { infrastructures }\end{array}$} & \multirow[t]{4}{*}{0.3722} & Urban parks & 0.1586 \\
\hline & & & & Urban squares & 0.0979 \\
\hline & & & & Urban waterfront recreation space & 0.0754 \\
\hline & & & & Sports and fitness venues & 0.0602 \\
\hline & & \multirow{3}{*}{$\begin{array}{l}\text { Public activities } \\
\text { places }\end{array}$} & \multirow[t]{3}{*}{0.3000} & Indoor cultural and sports facilities & 0.1000 \\
\hline & & & & Cultural and educational space & 0.0900 \\
\hline & & & & Historical and cultural blocks & 0.0901 \\
\hline \multirow{3}{*}{$\begin{array}{c}\text { Commercial } \\
\text { recreation } \\
\text { space }\end{array}$} & \multirow[t]{3}{*}{0.3278} & Mass & \multirow[t]{2}{*}{0.1920} & Golf courses & 0.0530 \\
\hline & & $\begin{array}{l}\text { entertainment } \\
\text { places }\end{array}$ & & $\begin{array}{l}\text { Commercial recreation space and } \\
\text { commercial facilities }\end{array}$ & 0.1333 \\
\hline & & $\begin{array}{l}\text { Value-added } \\
\text { leisure places }\end{array}$ & 0.1358 & Cultural and entertainment places & 0.1358 \\
\hline
\end{tabular}


The accessibility index of a certain type of recreation space $=$ quality accessibility index + time interval accessibility index + satisfaction accessibility index

The equity index of a certain type of recreation space $=$ weights $*$ the accessibility index

The equity index of overall studied recreation space is the sum of the equity indexes of all types of recreation space.

\subsection{Data Investigation and Analysis Methods}

\subsubsection{Location Investigation}

In order to comprehensively investigate the recreation spatial experience of residents in the Futian District, Shenzhen, the questionnaires were distributed at ten Futian's small areas divided by the road network, including Meilin, Xiangmi Lake, Lianhua, Huafu, Yuanling, Huaqiang North, Nanyuan, Futian, Fubao and Shatou, covering the most area of Futian District.

\subsubsection{Questionnaire Investigation and Analysis Methods}

In this study, the author divides Futian District into ten small areas: Meilin, Xiangmihu, Lianhua, Huafu, Yuanling, Huaqiangbei, Nanyuan, Futian, Fubao and Shatou, and issues questionnaires in these ten areas. A total of 330 questionnaires were distributed at ten small areas of the Futian District, and 300 questionnaires were retrieved with effective rate of $91 \%$. The collected data was analyzed by SPSS20.0 software.

\section{Data Analysis and Results}

\subsection{Basic Information of Samples}

The results show that the proportions of 140 males and 160 females had no significant difference. The age of 275 samples is mainly distributed among 36 and 55 , accounting for $91 \%$. Their educational backgrounds are mainly bachelor's degree, followed by junior high school, senior high school and other equivalence. The majority of occupations are general managers, general technicians or teachers.

There are 98 people with the monthly income of 4001 - 6000 yuan, accounting for the most. According to the Statistics Yearbook of Shenzhen in 2015, people's average monthly income was about 6054 yuan in 2014. In this study, people whose monthly income is more than 6000 yuan accounted for only $30 \%$ of the total, indicating that the monthly income of $60 \%$ was lower than that of the average in Shenzhen (Table 3).

\subsection{Social Class Division of Samples}

In order to compare the equity of recreation space among residents of different social classes, the samples are divided into different classes. Referring to relevant 
Table 3. Basic information of samples.

\begin{tabular}{|c|c|c|}
\hline Items & Details & Numbers \\
\hline \multirow[t]{2}{*}{ Gender } & Male & 140 \\
\hline & Female & 160 \\
\hline \multirow[t]{7}{*}{ Age } & 12 and under & 0 \\
\hline & $13-18$ & 4 \\
\hline & $19-25$ & 121 \\
\hline & $26-35$ & 112 \\
\hline & $36-55$ & 275 \\
\hline & $56-65$ & 8 \\
\hline & 65 and over & 0 \\
\hline \multirow{7}{*}{$\begin{array}{l}\text { Educational } \\
\text { background }\end{array}$} & Primary school and below & 0 \\
\hline & Junior middle school & 56 \\
\hline & $\begin{array}{l}\text { High school, technical secondary school, } \\
\text { technical secondary school }\end{array}$ & 52 \\
\hline & Junior college education (including higher vocational education) & 18 \\
\hline & Bachelor degree & 168 \\
\hline & Master degree & 6 \\
\hline & Doctor and above & 0 \\
\hline \multirow[t]{7}{*}{ Career } & Temporary workers, unemployed or students & 52 \\
\hline & Manual workers or staff of enterprises and institutions & 46 \\
\hline & Individual worker & 30 \\
\hline & General office staff & 44 \\
\hline & Ggeneral managers, general technicians or teachers & 72 \\
\hline & $\begin{array}{l}\text { Party and government organs, middle-level managers of enterprises and } \\
\text { institutions, middle-level technicians, middle-level professional titles or } \\
\text { owners and sole proprietors of medium-sized private enterprises }\end{array}$ & 48 \\
\hline & $\begin{array}{l}\text { Senior managers, senior technicians or senior titles of Party and } \\
\text { government organs, enterprises and institutions }\end{array}$ & 8 \\
\hline \multirow{7}{*}{$\begin{array}{l}\text { Monthly } \\
\text { income }\end{array}$} & $<2000 \mathrm{RMB}$ & 35 \\
\hline & $2000-4000 \mathrm{RMB}$ & 77 \\
\hline & $4001-6000 \mathrm{RMB}$ & 98 \\
\hline & $6001-8000$ RMB & 15 \\
\hline & $8001-10,000 \mathrm{RMB}$ & 33 \\
\hline & $10001-20,000 \mathrm{RMB}$ & 19 \\
\hline & $>20,000 \mathrm{RMB}$ & 23 \\
\hline
\end{tabular}

literature's social class division method, divided indicators are determined by respondents' educational background, occupation and monthly income (Tian, Yang, \& Liu, 2014), and three indicators are assigned the scores of " $1,2,3,4,5$, 
6, 7" respectively. The total scores are the sums of the scores of respondents' educational background, occupation and monthly income. Finally, the social groups can be divided into strong class, middle class and weak class according to the total scores. According to the statistics of the survey results, the population of three social classes has been shown in Figure 1.

\subsection{Reliability Analysis}

In this study, the Cronbach's a coefficient in SPSS20.0 software is used to test the reliability of the questionnaire and ensure the accuracy, consistency and stability of the test results. It's generally acknowledged that the questionnaire has a good reliability with the Cronbach's a coefficient greater than 0.85 . In this study, the Cronbach's a coefficient of the overall questionnaire is 0.897 , greater than 0.85 , and the Cronbach's a coefficients of each item are all greater than 0.85 , indicating the good reliability of the questionnaire.

\subsection{Analysis of the Accessibility of Public Recreation Space}

\subsubsection{Accessibility of Types of Public Recreation Space to Different Social Classes}

According to the quantitative method of accessibility evaluation, the mean values of range standardization are used as the accessibility index in this study. The accessibility indexes of ten types of recreation space can be calculated with formula 2.1 and formula 2.2, and the accessibility indexes of recreation space among different social classes can be calculated by classification. The accessibility index refers to not only residents' evaluation of recreation space but also its spatial equity. The higher index represents higher residents' evaluation and their more equal opportunities for public recreation space. The type of recreation space with higher accessibility index also indicates that it is more able to meets public's recreational needs. The results can be seen in Table 4.

\section{Population}

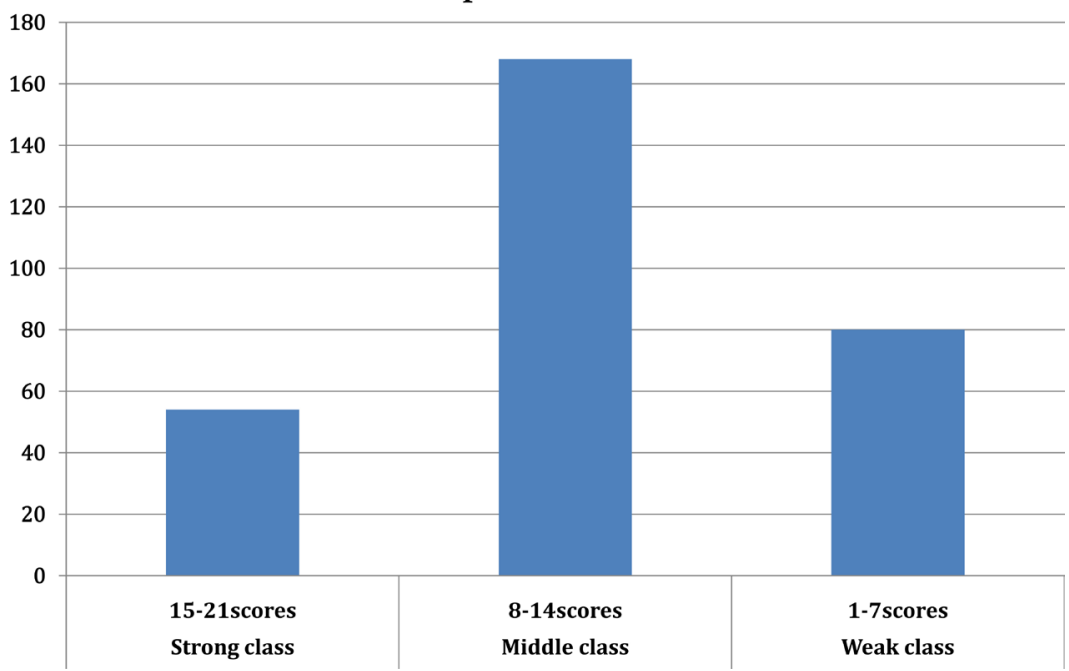

Figure 1. Population distribution of three social classes. 
Table 4. Accessibility indexes of three social classes.

\begin{tabular}{lccc}
\hline \multicolumn{1}{c}{ Types of recreation space } & Strong class & Middle class & Weak class \\
\hline 1 Urban parks & 0.33 & 0.35 & 0.32 \\
2 Urban squares & 0.19 & 0.21 & 0.18 \\
3 Urban waterfront recreation space & 0.12 & 0.15 & 0.11 \\
4 Sports and fitness venues & 0.11 & 0.10 & 0.11 \\
5 Indoor cultural and sports facilities & 0.16 & 0.16 & 0.09 \\
6 Cultural and educational space & 0.15 & 0.14 & 0.17 \\
7 Historical and cultural blocks & 0.14 & 0.16 & 0.17 \\
8 Golf courses & 0.09 & 0.06 & 0.03 \\
9 Commercial recreation space and commercial facilities & 0.26 & 0.30 & 0.27 \\
10 Cultural and entertainment places & 0.20 & 0.24 & 0.23 \\
Total accessibility index & 1.8 & 1.89 & 1.7 \\
\hline
\end{tabular}

From the results of the analysis, it can be concluded that the middle class has the highest total availability index. From the perspective of sharing indicators, the accessibility of urban parks is the highest, followed by commercial recreation space and commercial facilities, cultural and entertainment places and urban squares. Due to the limitation of distance, the availability of urban waterfront recreation space, sports and fitness venues, indoor cultural and sports facilities and Cultural and educational space is low. The lowest availability is golf course, because of its high entry threshold and low utilization rate, which should not be set in urban space.

\subsubsection{Overall Accessibility of Different Recreation Space}

The accessibility indexes of third-level indicators are the mean values of recreation space indexes among strong class, middle class and weak class. The total accessibility index is the sums of the accessibility indexes of third-level indicators. The accessibility indexes of second-level indicators are the sums of those of third-level indicators and accessibility indexes of first-level indicators are the sums of those of second-level indicators. The results are shown in Table 4 and Table 5.

\subsection{Empirical Study Analysis and Results}

\subsubsection{The Accessibility Index of Public Recreation Space Is Higher Than That of Commercial Recreation Space}

The statistical results show that the accessibility index of public recreation space is higher than that of commercial recreation space $(1.20>0.55)$, indicating that residents have a higher evaluation of public recreation space, that is, residents have more equal opportunities to enjoy public recreation space.

According to related statistics, the area of public recreation space in the Futian District, Shenzhen is about 0.35 million square meters and the area of commercial 
recreation space is about 2 million square meters, which is much larger. It indicates that residents' objective factors, such as their income, educational background and other constraints lead to their low accessibility of commercial recreation space.

\subsubsection{Comparison of Accessibility Indexes of 10 Types of Recreation Space}

The results of the accessibility indexes among different social classes show that there exists little difference in the evaluation of 10 types of recreation space, such as urban parks, urban squares and so on. The accessibility index of urban parks is the highest, followed by that of commercial recreation space and commercial facilities and those of golf courses. Sports and fitness venues and urban waterfront recreation space are the lowest. Figure 2 shows the results in details.

The accessibility index of golf courses is the lowest and residents have the lowest accessibility of this type of recreation resource. It's reported that the area of Shenzhen golf courses is 3 times of the area of community parks. While the per capita area of community park is only $0.34 \mathrm{~m}^{2}$, indicating that its high threshold is the main reason of golf courses' lowest accessibility.

The accessibility index of sports and fitness venues is relatively low. There are 1985 stadiums and 146.9 kilometers of green ways in the Futian District. Although there are large numbers and areas of sports and fitness venues, residents can not equally enjoy them. The main reasons are as follows. Firstly, the unreasonable venues allocation hinders residents' access to sports and fitness resources. Secondly, residents are lack of awareness of physical fitness and relevant motivation. According to statistics, $16 \%$ of the residents take more than $30 \mathrm{mi}$ nutes to get to the sports and fitness venues, and $19.9 \%$ of the residents have hardly been there.

Table 5. Accessibility indexes of each indicator.

\begin{tabular}{|c|c|c|c|c|c|}
\hline First-level indicators & $\begin{array}{l}\text { Accessibility } \\
\text { index }\end{array}$ & Second-level indicators & $\begin{array}{l}\text { Accessibility } \\
\text { index }\end{array}$ & Third-level indicators & $\begin{array}{l}\text { Accessibility } \\
\text { index }\end{array}$ \\
\hline \multirow[t]{6}{*}{ Public recreation space } & 1.20 & Public infrastructures & 0.75 & 1 Urban parks & 0.33 \\
\hline & & & & 2 Urban squares & 0.19 \\
\hline & & & & 3 Urban waterfront recreation space & 0.13 \\
\hline & & Public activities places & 0.45 & 5 Indoor cultural and sports facilities & 0.14 \\
\hline & & & & 6 Cultural and educational space & 0.15 \\
\hline & & & & 7 Historical and cultural blocks & 0.16 \\
\hline \multirow{2}{*}{$\begin{array}{c}\text { Commercial recreation } \\
\text { space }\end{array}$} & 0.55 & Mass entertainment places & 0.35 & 8 Golf courses & 0.06 \\
\hline & & Value-added leisure places & 0.20 & 10 Cultural and entertainment places & 0.22 \\
\hline Total accessibility index & & & 1.75 & & \\
\hline
\end{tabular}




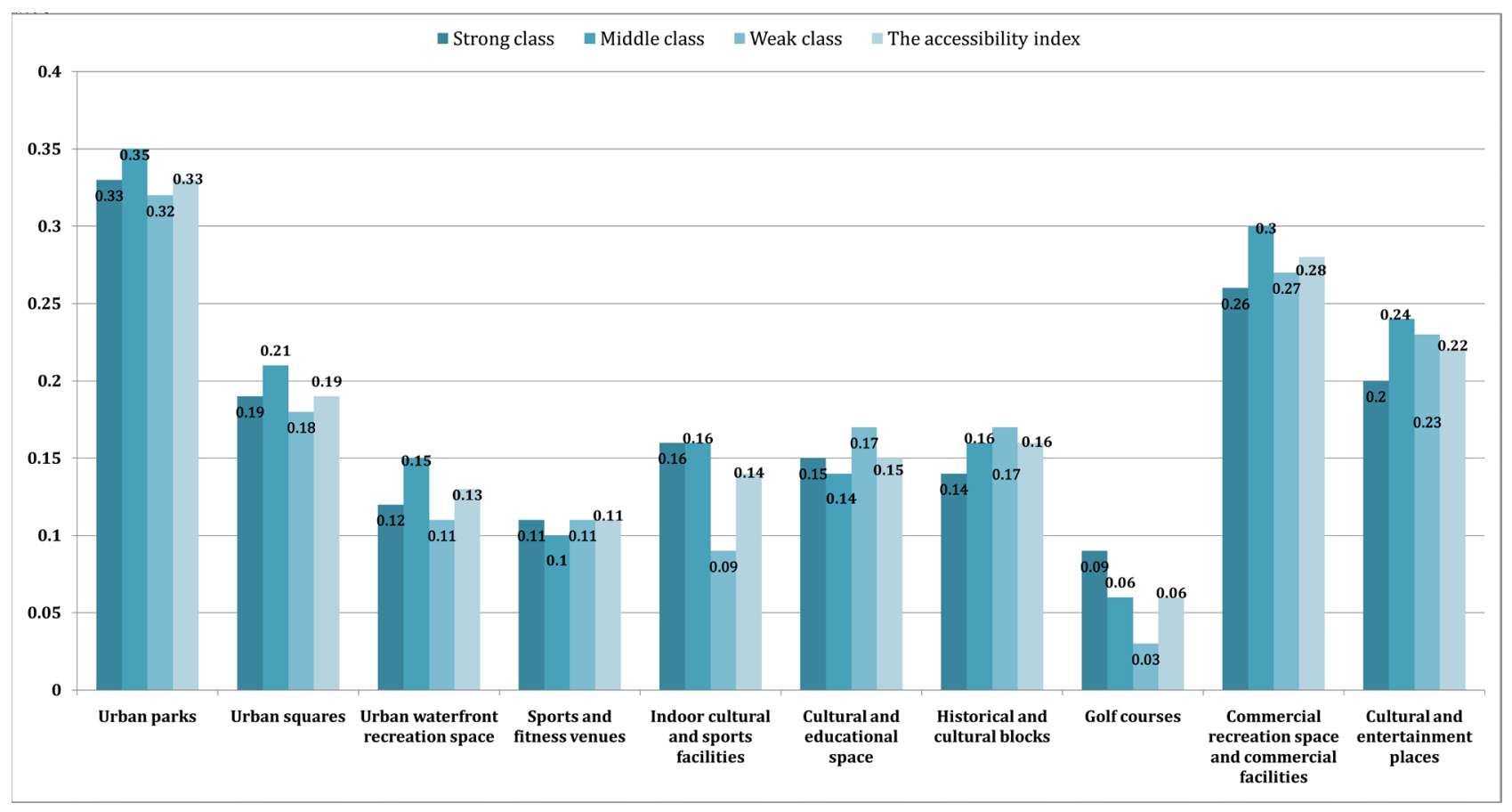

Figure 2. The accessibility indexes.

The accessibility index of urban waterfront recreation space is also relatively low, which is mainly due to the reason that the waterfront space is far away from residential areas with low accessibility and low frequency.

\subsubsection{Equity Analysis among Different Social Classes}

1) Middle class has the highest evaluation of recreation space.

The results show that the order of the accessibility indexes of each class is: middle class $(1.89)>$ strong class $(1.80)>$ weak class $(1.70)$. The middle class group has the highest evaluation of the quality, time interval and satisfaction of recreation space, and strong class group also has a relatively high evaluation of those of recreation space. However, weak class group is passive when enjoying the urban recreation space and has a relatively low evaluation of recreation space because of their low monthly income and low educational background.

2) Class equity of types of recreation space.

The results whose details are shown in Figure 2 showed that the middle class has a higher evaluation of ten types of recreation space with the higher accessibility index, followed by the strong class with relatively lower accessibility indexes of them. While the weak class is in the lowest accessibility indexes of ten types of recreation space, among which the accessibility indexes of "urban squares", "cultural and educational space" and "commercial recreation space and commercial facilities" are still relatively high.

\section{Conclusion and Discussion}

\subsection{Research Conclusion}

Taking the recreation space in the Futian District as an example, this study aims 
to construct the spatial equity evaluation system of recreation space in the central urban region based on residents' experience. The equity of recreation space in the Futian District, Shenzhen is measured from the perspectives of quality, time interval and satisfaction, and the experiential differences of types of recreation space among different social classes, that is, the equity of residents' enjoyment of recreation space, is discussed in this paper. Different from those of previous studies, the research conclusions are as follows.

\subsubsection{There Is Little Difference in Total Spatial Equity among Three Social Classes}

There is little difference in the spatial equity indexes among the strong class, middle class and weak class, that is, the spatial equity of three social classes is not much different. Among this, the spatial equity of the middle class is slightly higher than that of strong class, and the spatial equity of weak class is the lowest.

The quality satisfactions of ten types of recreation space of strong class and middle class are not much different. For weak class, there is a low quality accessibility of golf courses and indoor cultural and sports facilities. For middle class, there is a relatively low quality accessibility of golf courses mainly because of the high threshold of these recreation spaces.

Weak class chooses their recreation scope mostly around their residence and prefers typical urban parks and urban squares. Their evaluation of accessibility of time interval is higher than those of quality and satisfaction. Strong class and middle class think highly of the accessibility of time interval of public recreation space. They have a wider range of choices than weak class. However, the accessibility of time interval of golf courses among three social classes is relatively low.

The recreation preference of three social classes can be deduced from their satisfaction accessibility of types of recreation space. The strong class is more concerned about privacy and high quality of recreation space. The middle class accepts equally with ten types of recreation space. The weak class has a higher evaluation of public recreation space because of their limitation by various factors.

\subsubsection{The Total Accessibility Index of Public Recreation Space Is Higher Than That of Commercial Recreation Space}

By comparing the spatial equity indexes of different types of recreation space, it is found that the equity of public recreation space is higher than that of commercial recreation space. However, among the rankings of each type of recreation space, the urban parks of public recreation space ranks first, followed by commercial recreation space and commercial facilities and cultural and entertainment places of commercial recreation space.

The equity of public recreation space is higher than that of commercial recreation space, which is mainly due to the fact that there are more public recreation spaces in the studied area. In addition to the accessibility of urban parks, urban squares and urban waterfront recreation space, that of other public 
recreation space, especially of sports and fitness venues, is relatively low. The recreation space of urban waterfront recreation space, indoor cultural and sports facilities, cultural and educational space, historical and cultural blocks, golf courses and cultural and entertainment places are not indispensable in residents' daily life. Therefore, their spatial equity is at the middle level.

The reasons of the research conclusions are analyzed from the following four aspects: unbalanced allocation of resources, the preference of three social classes for types of recreation space, leisure time and residential places, and leisure consciousness.

\subsection{Discussion}

\subsubsection{The Unbalanced Allocation of Resources Affects Residents' Spatial Accessibility}

The unbalanced allocation of recreation space has led to the weak class's low accessibility, that is, poor equity. There are two main reasons for the unbalanced allocation of recreation resources. Firstly, the characteristics of recreation space determine the distribution of recreation resources. Urban parks and urban squares are in the categories of public infrastructures, and commercial recreation space and commercial facilities are the important economic sources of the central urban region of the studied area. The above three types of recreation space are most widely distributed because of their necessary function. The distribution of most urban waterfront recreation space is subject to the resources of natural rivers and seas. As a result, this type of recreation resource is less because of the location of Shenzhen. The recreation space of sports and fitness venues, indoor cultural and sports facilities, cultural and educational space, historical and cultural blocks, golf courses and cultural and entertainment places is not indispensable in residents' daily life. It is distributed according to residents' needs and consumption capacity. Therefore, the distribution of this recreation space leads to spatial gathering according to social classes, resulting in the unbalanced distribution of recreation resources.

Secondly, the problems left over from the history of urban planning in Shenzhen have the impact on the distribution of recreation resources. With the rapid development of Shenzhen, the commercial groups have independently planned and developed the recreation programs in each district. They pay more attention to the commercial interests and neglect the overall planning of recreation space and the sustainable development of urban recreation space in the future. Lack of the strategic development mode, the recreation resources in Shenzhen are unbalanced in numbers and residents have different accessibility of recreation resources.

\subsubsection{Residents' Preference and Accessibility of Recreation Space Lead to Their Different Evaluation}

Three social classes have different choices and preferences of ten types of recreation space. The accessibility indexes of some types of recreation space with 
strong class are lower than those with middle class and weak class. Strong class prefers the paid, quiet, healthy and private recreation spatial such as golf courses, cultural and educational spatial and exclusive commercial recreation space. While the middle class and weak class prefer free and lively recreation place such as urban parks, urban squares and other places. Therefore, with the strong class evaluating 10 types of recreation space, the quality and satisfaction evaluation are determined by their preferences, forming the situation of different evaluation with different residents.

\subsubsection{Leisure Time and Location Affect Residents' Access to Recreation Resources within Study Area}

The results show that residents' leisure time and residential places affect their recreation space. Their daily recreation space can be around the residential places or across their residential district, which mainly depends on the distance from the recreation space to their residential places, which is also called Boundary Effect.

\subsubsection{Lack of Leisure Consciousness Weakens Residents' Initiative to Obtain Recreation Resources}

Although people pay more and more attention to leisure and recreation, three social classes choose different ways of recreation because of their consciousness, income and time. In the interview, it's found that the leisure consciousness of different social classes is different. The initiative of weak class to obtain recreation resources is weaker than those of strong class and middle class. Some young migrant workers have said that they prefer to stay at home rather than go out in their leisure time.

\subsection{Conclusion}

Different classes have different accessibility to types of recreation space due to their own objective and subjective reasons. In addition, the layout of recreation space also determines the accessibility of different classes. From the perspective of recreation needs of different classes, the layout of urban recreation space and urban living environment should be improved. From the perspective of urban planning and management services, the urban recreation space should be regulated and controlled macroscopically and the recreation resources must be allocated reasonably to enhance the unbalanced present situation. The utilization rate of idle recreation space should be boosted to increase residents' accessibility. Last but not least, it is necessary to strengthen the publicity of recreation space and improve residents' leisure consciousness in order to increase residents' equity of urban recreation space in the future.

\section{Conflicts of Interest}

The authors declare no conflicts of interest regarding the publication of this paper. 


\section{References}

Beeco, J. A., \& Brown, G. (2013). Integrating Spatial, Spatial Tools, and Spatial Analysis into the Human Dimensions of Parks and Outdoor Recreation. Applied Geography, 38, 76-85. https://doi.org/10.1016/j.apgeog.2012.11.013

Bolitzer, B., \& Netusil, N. R. (2000). The Impact of Open Spatials on Property Values in Portland, Oregon. Journal of Environmental Management, 59, 185-193. https://doi.org/10.1006/jema.2000.0351

Cao, X., \& Qiao, H. W. (2014). Spatial Justice Must Be Emphasized in the Construction of New Urbanization. Guangming Daily, 6, 18.

Chen, W., \& Wang, Y. F. (2009). A Study on the Fairness Evaluation of the Location Distribution of Urban Parks. Journal of Anhui Normal University (Natural Science Edition), 4, 373-377.

Chen, Y. (2013). Theory Conctruction and Strategies of City Recreation Planning. Ph.D. Dissertation, Guangzhou: South China University of Techonogy.

Comber, A., Brunsdon, C., \& Green, E. (2008). Using a GIS-Based Network Analysis to Determine Urban Green Spatial Accessibility for Different Ethnic and Religious Groups. Landscape and Urban Planning, 86, 103-114. https://doi.org/10.1016/j.landurbplan.2008.01.002

Cutts, B. B., Darby, K. J., Boone, C. G., et al. (2009). City Structure, Obesity, and Environmental Justice: An Integrated Analysis of Physical and Social Barriers to Walkable Streets and Park Access. Social Science \& Medicine, 69, 1314-1322. https://doi.org/10.1016/j.socscimed.2009.08.020

Erkip, F. (Beler) (1997). The Distribution of Urban Public Services: The Case of Parks and Recreational Services in Ankara. Cities, 14, 353-361. https://doi.org/10.1016/S0264-2751(97)00026-7

Gao, J. B., Zhou, C. S., \& Ye, C. D. (2010). The Equitable Distribution of Public Services in Guangzhou/Gao Junbo, Zhou Chunshan, Ye Changdong. Planner Forum, 4, 12-18.

Hu, Y., \& Cai, Y. L. (2017). Analyzing the Spatial Equity of Urban Parkss' Social Functioning Quantitatively: A Case Study for the Central Area of Shanghai. Journal of East China Normal University (Natural Science), 1, 91-103.

Jiang, H. Y., Zhou, C. S., \& Xiao, R. B. (2010). Spatial Differentiation and Social Equity of Pubic Parks in Guangzhou. City Planning Review, 4, 43-48.

Jiang, K. F., Zhong, W. J., \& Yu, Y. P. et al. (2015). Study on the Measurement of Spatial Accessibility and Fairness of Urban Elderly Care Facilities-A Case Study of Gulou District, Nanjing. Proceedings of 2015 China Urban Planning Annual Conference, 2015 China Urban Planning Annual Meeting, Guizhou, 19 September 2015, 619-627.

Kim, J. W. (2015). Measuring the Equity of Recreation Opportunity: A Spatial Statistical Approach. M.A. Thesis, East Lansing, MI: Michigan State University.

Ma, H. D. (2005). A Glance on Urban Planning for Recreational Ground in Western Countries. Qilu Journal, 6, 149-155.

Mao, J. (2014). Study on the Evaluation of Urban Community Recreational Spatial Justice: A Case Study of Three Communities of Xi'an. M.A. Thesis, Xi'an: Xi'an International Studies University.

Qiu, Y. (2015). Research on the Satisfaction Experience of Urban Fitness Leisure Spatials: A Case Study of Commercial Fitness Leisure Spatial in Fuzhou. M.A. Thesis, Fuzhou: Fujian Normal University.

Ren, Z. (2014). Logic of Justice on the Production of Spatial-From the Perspective of 
Reconstruction of Justice and Critique of the Production of Spatial. Ph.D. Dissertation, Suzhou: Soochow University.

Tan, P. Y., \& Samsudin, R. (2017). Effects of Spatial Scale on Assessment of Spatial Equity of Urban Park Provision. Landscape and Urban Planning, 158, 139-154. https://doi.org/10.1016/j.landurbplan.2016.11.001

Tang, X. C. (2014). Research on David Harvey's Urban Spatial Thought. Beijing: People's Publishing House.

Tang, Z. L., \& Gu, Z. (2015). An Evaluation of Social Performance in the Distribution of Urban Parks in the Central City Shanghai: From Spatial Equity to Social Equity. Urban Planning Forum, 2, 48-56.

Tian, H., Yang, Y., \& Liu, Y. A. (2014). Comparative Study of Sports Consumption Willingness and Behavior in Five Different Social Classes. Journal of Beijing Sport University, 10, 51-55.

Wang, L. J. (2014). Research on Spatial Equity of Urban Public Facilities: A Case Study of Chongqing. Ph.D. Dissertation, Chongqing: Chongqing University.

Wei, F. Q., \& Xi, Y. T. (2016). SHU Tian Cole. Development Concept and Strategy of Urban Recreation spatial in the Perspective of Spatial Justice-Based on the Experience of United States. Journal of Human Settlements in West China, 5, 51-56.

Wu, J. L. (2014). Research on the Spatial Justice of Urban Tourism Community: A Case of the Big Wild Goose Pagoda Culture and Leisure Tourism Community of Xi'an. M.A. Thesis, Xi'an: Xi'an International Studies University.

Wu, J. S., Si, M. L., \& Li, W. F. (2016). Spatial Equity Analysis of Urban Green spatial from the Perspective of Balance between Supply and Demand: A Case Study of Futian District, Shenzhen, China. Chinese Journal of Applied Ecology, 9, 2831-2838.

Yin, H. W., \& Xu, J. G. (2009).Spatial Accessibility and Equity of Parks in Shanghai. Urban Studies, 6, 71-76.

Yin, H. W., Kong, F. H., \& Zong, Y. G. (2008). Accessibility and Equity Assessment on Urban Green Spatial. Acta Ecologica Sinica, 7, 3375-3383. 